\title{
Proximal algorithms for a class of mixed equilibrium problems
}

Yisheng Song ${ }^{1,2^{*}}$ and Qingnian Zhang ${ }^{3}$

"Correspondence:

songyisheng123@yahoo.com.cn

${ }^{1}$ College of Mathematics and Information Science, Henan Normal

University, Xinxiang, Henan 453007,

P.R. China

${ }^{2}$ Department of Applied

Mathematics, The Hong Kong

Polytechnic University, Hung Hom,

Kowloon, Hong Kong, P.R. China

Full list of author information is

available at the end of the article

\begin{abstract}
We present two proximal algorithms for solving the mixed equilibrium problems. Under some simpler framework, the strong and weak convergence of the sequences defined by two general algorithms is respectively obtained. In particular, we deal with several iterative schemes in a united way and apply our algorithms for solving the classical equilibrium problem, the minimization problem, the classical variational inequality problem and the generalized variational inequality problem. Our results properly include some corresponding results in this field as a special case.

MSC: 47H06; 47J05; 47J25; 47H10; 90C33; 90C25; 49M45; 65C25; 49J40; 65J15; 47H09
\end{abstract}

Keywords: mixed equilibrium problem; proximal algorithm; variational inequality

\section{Introduction}

Throughout the paper, $H$ is a real Hilbert space with inner product $\langle\cdot, \cdot\rangle$ and induced norm $\|\cdot\|$. Let $K$ be a nonempty closed convex subset of $H, F: K \times K \rightarrow \mathbb{R}$ be a bifunction and $\varphi: K \rightarrow \mathbb{R} \cup\{+\infty\}$ be a proper generalized real valued function, where $\mathbb{R}$ is the set of real numbers. Our interest is in finding a solution to the following problem which is referred to as the mixed equilibrium problem (for short, MEP) for $F, \varphi$

$$
\text { find } x \in K \text { such that } F(x, y)+\varphi(y)-\varphi(x) \geq 0, \quad \forall y \in K .
$$

We denote the set of solutions for MEP by

$$
\operatorname{MEP}(F, \varphi)=\{x \in K ; F(x, y)+\varphi(y)-\varphi(x) \geq 0, \forall y \in K\} .
$$

Obviously, MEP (1.1) is a classical equilibrium problem (for short, EP) for $F$ when $\varphi \equiv 0$

$$
\text { find } x \in K \text { such that } F(x, y) \geq 0, \quad \forall y \in K \text {. }
$$

The set $\operatorname{MEP}(F, 0)$ of solutions of $\mathrm{EP}(1.2)$ is denoted by $\operatorname{EP}(F)$.

If $F \equiv 0$, then MEP (1.1) becomes the minimization problem (for short, MP) for a function $\varphi$

$$
\text { find } x \in K \text { such that } \varphi(y) \geq \varphi(x), \quad \forall y \in K,
$$

and $\operatorname{MEP}(0, \varphi)$ is denoted by $\operatorname{Argmin}(\varphi)$.

๑ 2012 Song and Zhang; licensee Springer. This is an Open Access article distributed under the terms of the Creative Commons Attribution License (http://creativecommons.org/licenses/by/2.0), which permits unrestricted use, distribution, and reproduction in any medium, provided the original work is properly cited. 
Given a mapping $T: K \rightarrow H$, let $F(x, y)=\langle T x, y-x\rangle$ for all $x, y \in K$. Then $z \in \operatorname{EP}(F)$ if and only if $\langle T z, y-z\rangle \geq 0$ for all $y \in K$, i.e., EP (1.2) turns into a classical variational inequality problem (for short, VIP) for $T$

$$
\text { find } x \in K \text { such that }\langle T x, y-x\rangle \geq 0, \quad \forall y \in K \text {. }
$$

At the same time, MEP (1.1) also reduces a generalized variational inequality problem (for short, GVIP) for a mapping $T$ and a function $\varphi$

$$
\text { find } x \in K \text { such that }\langle T x, y-x\rangle+\varphi(y)-\varphi(x) \geq 0 \quad \text { for all } y \in K \text {, }
$$

and denote

$$
\operatorname{GVIP}(T, \varphi, K)=\{x \in K ;\langle T x, y-x\rangle+\varphi(y)-\varphi(x) \geq 0 \text { for all } y \in K\}
$$

and $\operatorname{VIP}(T, K)=\operatorname{GVIP}(T, 0, K)$.

The mixed equilibrium problem (MEP) is very interesting because it covers mathematical programs and optimization problems over equilibrium constraints, hierarchical minimization problems, variational inequality, complementarity problems, monotone inclusion problems, saddle point problems, Nash equilibria in noncooperative games as well as certain fixed point problems. In other words, the mixed equilibrium problem unifies several problems arising from engineering, physics, statistics, computer science, optimization theory, operation research, economics and others. The interest of this problem is that it unites all these particular problems in a convenient way. Moreover, many methods devoted to solving one of these problems can be extended, with suitable modifications, to solving the mixed equilibrium problem (MEP).

In the last 20 years or so, many mathematical works have been devoted to studying the method for finding an approximate solution of $\operatorname{EP}(F)$ with various types of additional conditions. Moudafi [1] extended the proximal method to monotone equilibrium problems and Konnov [2] used the proximal method to solve equilibrium problems with weakly monotone bifunctions. In 2005, Combettes and Hirstoaga [3] introduced an iterative scheme of finding the best approximation to the initial data when $\operatorname{EP}(F)$ is nonempty and they also proved a strong convergence theorem under the condition $\lim _{n \rightarrow \infty} r_{n}=+\infty$. Song and Zheng [4] and Song, Kang and Cho [5] considered the convergence of a Halperntype iteration for $\mathrm{EP}(F)$. The bundle methods and extragradient methods were extended to equilibrium problems in [6] and [7]. In 2007, Takahashi and Takahashi [8] introduced the viscosity approximation method for finding a common element of the set of solutions of an equilibrium problem $\mathrm{EP}(F)$ and the set of fixed points of a nonexpansive mapping $T$ under the conditions $\liminf _{n \rightarrow \infty} r_{n}=+\infty$ and $\sum_{n=0}^{+\infty}\left\|r_{n}-r_{n+1}\right\|<+\infty$. Subsequently, the above viscosity approximation method was studied by different mathematicians using varying environmental conditions; see references [9-13] for details. Recently, Moudafi [14] showed weak convergence of proximal methods for a class of bilevel monotone equilibrium problems. For other solution methods regarding the equilibrium problems see $[2,15-22]$.

In this paper, our main objective is to show the mixed equilibrium problem (1.1) can be solved by two very simple proximal methods under simpler conditions, where a bifunction $F$ and a function $\varphi$ satisfy the following standard assumptions. 
Condition 1.1 The function $\varphi: K \rightarrow \mathbb{R} \cup\{+\infty\}$ is a proper lower semicontinuous convex function and the bifunction $F: K \times K \rightarrow \mathbb{R}$ satisfies the following:

(A1) $F(x, x)=0$ for all $x \in K$;

(A2) $F$ is monotone, i.e., $F(x, y)+F(y, x) \leq 0$ for all $x, y \in K$;

(A3) for each $x, y, z \in K, \lim \sup _{t \rightarrow 0^{+}} F(t z+(1-t) x, y) \leq F(x, y)$;

(A4) for each $x \in K, y \mapsto F(x, y)$ is convex and lower semicontinuous.

To this end, we introduce two proximal algorithms.

Algorithm 1 For any anchor $u \in K$ and initialization $x_{0} \in K$, if $x_{n}(n \geq 0)$ is the current iterate and $\alpha_{n}, r_{n}$ are the current parameters, then $x_{n+1} \in K$ is defined iteratively by

$$
\left\{\begin{array}{l}
F\left(u_{n}, y\right)+\varphi(y)-\varphi\left(u_{n}\right)+\frac{1}{r_{n}}\left\langle y-u_{n}, u_{n}-x_{n}\right\rangle \geq 0, \\
x_{n+1}=\alpha_{n} u+\left(1-\alpha_{n}\right) u_{n}, \quad \forall y \in K, n \geq 0 .
\end{array}\right.
$$

We will show $\left\{x_{n}\right\}$ strongly converges to some element $x^{*}$ of $\operatorname{MEP}(F, \varphi)$ if only $\left\{\alpha_{n}\right\} \subset$ $(0,1)$ and $\left\{r_{n}\right\} \subset(0,+\infty)$ satisfy the following simple conditions:

$$
\text { (C1) } \lim _{n \rightarrow \infty} \alpha_{n}=0, \quad \text { (C2) } \sum_{n=1}^{+\infty} \alpha_{n}=+\infty, \quad \text { (C3) } \liminf _{n \rightarrow \infty} r_{n}>0 \text {. }
$$

Algorithm 2 For any initialization $x_{0} \in K$, if $x_{n}(n \geq 0)$ is the current iterate and $\alpha_{n}, r_{n}$ are the current parameters, then $x_{n+1} \in K$ is given iteratively by

$$
\left\{\begin{array}{l}
F\left(u_{n}, y\right)+\varphi(y)-\varphi\left(u_{n}\right)+\frac{1}{r_{n}}\left\langle y-u_{n}, u_{n}-x_{n}\right\rangle \geq 0, \\
x_{n+1}=\alpha_{n} x_{n}+\left(1-\alpha_{n}\right) u_{n}, \quad \forall y \in K, n \geq 0 .
\end{array}\right.
$$

We will prove $\left\{x_{n}\right\}$ weakly converges to some element $x^{\prime \prime}$ of $\operatorname{MEP}(F, \varphi)$ whenever $\left\{r_{n}\right\} \subset$ $(0,+\infty)$ and $\left\{\alpha_{n}\right\} \subset(0,1)$ only satisfy the simpler conditions

$$
\text { (C3) } \liminf _{n \rightarrow \infty} r_{n}>0 \text { and (C4) } \limsup _{n \rightarrow \infty} \alpha_{n}<1 \text {. }
$$

Some other proximal methods and the related strong and weak convergence results can be derived from our main theorem by particularizing the bifunction $F$, the function $H$ and the parameters $\alpha_{n}, r_{n}$. Our results treat several iterative schemes in a united way and properly include some results of $[3-5,8,20,21,23,24]$ as a special case.

The rest of the paper is organized as follows. In Section 2, we introduce some necessary lemmas and results, and show our algorithms are well defined. In Section 3, we study the strong convergence of a sequence iteratively given by Algorithm 1. In Section 4, we deal with the weak convergence of an iterative scheme defined by Algorithm 2. Some other proximal methods and the related results derived from our main theorems and some concluding remarks can be found in Section 5 .

\section{Preliminaries and basic results}

Let $\left\{x_{n}\right\}$ be a sequence in $H$. We write $x_{n} \rightarrow x$ to indicate that the sequence $\left\{x_{n}\right\}$ weakly converges to $x$; as usual, $x_{n} \rightarrow x$ will symbolize strong convergence. Let $F(T)=\{x \in H ; T x=$ 
$x$ be the set of all fixed points for a mapping $T$. In a real Hilbert space $H$, we have

$$
\|t x+(1-t) y\|^{2}=t\|x\|^{2}+(1-t)\|y\|^{2}-t(1-t)\|x-y\|^{2}
$$

for all $x, y \in H$ and $t \in[0,1]$. Let $K$ be a nonempty closed convex subset of $H$. Then for any $x \in H$, there exists a unique nearest point in $K$, denoted by $P_{K}(x)$, such that

$$
\left\|x-P_{K}(x)\right\| \leq\|x-y\| \quad \text { for all } y \in K \text {. }
$$

Such a $P_{K}$ is called the metric projection of $H$ onto $K$. We know that $P_{K}$ is firmly nonexpansive, i.e., for any $x, y \in H$,

$$
\left\|P_{K}(x)-P_{K}(y)\right\|^{2} \leq\left\langle P_{K}(x)-P_{K}(y), x-y\right\rangle
$$

Further, for $x \in H$ and $z \in K$,

$$
z=P_{K}(x) \quad \Leftrightarrow \quad\langle x-z, y-z\rangle \leq 0 \quad \text { for all } y \in K \text {. }
$$

For a bifunction $\Psi: K \times K \rightarrow \mathbb{R}$, we have the following lemmas which were also given in [17].

Lemma 2.1 (Blum-Oettli [17, Corollary 1]) Let $K$ be a nonempty closed convex subset of $H$ and $\Psi$ be a bifunction of $K \times K$ into $\mathbb{R}$ satisfying (A1)-(A4) in Condition 1.1. Let $r>0$ and $x \in H$. Then there exists $z \in K$ such that

$$
\Psi(z, y)+\frac{1}{r}\langle y-z, z-x\rangle \geq 0, \quad \forall y \in K
$$

Using a similar proof technique of Combettes-Hirstoaga [3, Lemma 2.12], also see Ceng and Yao [15, Lemma 3.1], Peng, Liou and Yao [16, Lemma 2.2] obtained the following lemma which guarantees that our algorithms are well defined.

Lemma 2.2 ([16, Lemma 2.2]) Let K be a nonempty closed convex subset of H. Suppose that the bifunction $F: K \times K \rightarrow \mathbb{R}$ and the function $\varphi: K \rightarrow \mathbb{R} \cup\{+\infty\}$ satisfy Condition 1.1. For $r>0$ and $x \in H$, define a mapping $T_{r}: H \rightarrow 2^{K}$ as follows:

$$
T_{r}(x)=\left\{z \in K: F(z, y)+\varphi(y)-\varphi(z)+\frac{1}{r}\langle y-z, z-x\rangle \geq 0, \forall y \in K\right\} .
$$

Then the following hold:

(1) the domain of $T_{r}$ is $H$.

(2) $T_{r}$ is single-valued and firmly nonexpansive, i.e., for any $x, y \in H$,

$$
\left\|T_{r}(x)-T_{r}(y)\right\|^{2} \leq\left\langle T_{r}(x)-T_{r}(y), x-y\right\rangle
$$

or equivalently,

$$
\left\|T_{r}(x)-T_{r}(y)\right\|^{2} \leq\|x-y\|^{2}-\left\|\left(x-T_{r}(x)\right)-\left(y-T_{r}(y)\right)\right\|^{2} .
$$


(3) $F\left(T_{r}\right)=\operatorname{MEP}(F, \varphi)$.

(4) $\operatorname{MEP}(F, \varphi)$ is closed and convex.

Lemma 2.3 was showed and used by several authors. For detailed proofs, see Liu [25] and $\mathrm{Xu}[26,27]$. Furthermore, a variant of Lemma 2.3 has already been used by Reich in [28, Theorem 1].

Lemma 2.3 Let $\left\{a_{n}\right\}$ be a sequence of nonnegative real numbers satisfying the property

$$
a_{n+1} \leq\left(1-t_{n}\right) a_{n}+t_{n} c_{n}, \quad \forall n \geq 0,
$$

where $\left\{t_{n}\right\}$ and $\left\{c_{n}\right\}$ satisfy the restrictions $\sum_{n=0}^{\infty} t_{n}=\infty$ and $\lim _{n} \sup _{n \rightarrow \infty} c_{n} \leq 0$. Then $\left\{a_{n}\right\}$ converges to zero as $n \rightarrow \infty$.

\section{Strong convergence of Algorithm 1}

In this section, we deal with an iterative scheme given by Algorithm 1 for finding an element of the set of solutions of the MEP (1.1) in a Hilbert space.

Theorem 3.1 Let $K$ be a nonempty closed convex subset of a real Hilbert space $H$. Assume that $a$ bifunction $F$ and a function $\varphi$ satisfy Condition 1.1 and $\operatorname{MEP}(F, \varphi) \neq \emptyset$. For any anchor $u \in K$ and initialization $x_{0} \in K$, let $\left\{x_{n}\right\}$ and $\left\{u_{n}\right\}$ be two sequences generated iteratively by

$$
\left\{\begin{array}{l}
F\left(u_{n}, y\right)+\varphi(y)-\varphi\left(u_{n}\right)+\frac{1}{r_{n}}\left\langle y-u_{n}, u_{n}-x_{n}\right\rangle \geq 0 \\
x_{n+1}=\alpha_{n} u+\left(1-\alpha_{n}\right) u_{n}, \quad \forall y \in K, n \geq 0
\end{array}\right.
$$

If only $\left\{\alpha_{n}\right\} \subset(0,1)$ and $\left\{r_{n}\right\} \subset(0,+\infty)$ satisfy

$$
\text { (C1) } \lim _{n \rightarrow \infty} \alpha_{n}=0, \quad \text { (C2) } \sum_{n=1}^{+\infty} \alpha_{n}=+\infty \quad \text { and } \quad \text { (C3) } \liminf _{n \rightarrow \infty} r_{n}>0
$$

then $\left\{x_{n}\right\}$ converge strongly to some element $x^{*}=P_{\operatorname{MEP}(F, \varphi)}(u)$ of $\operatorname{MEP}(F, \varphi)$.

Proof At first, we show that $\left\{x_{n}\right\}$ and $\left\{u_{n}\right\}$ are bounded. Taking $p \in \operatorname{MEP}(F, \varphi)$, it follows from Lemma 2.2 that $u_{n}=T_{r_{n}}\left(x_{n}\right)$ and

$$
\begin{aligned}
\left\|x_{n+1}-p\right\| & \leq\left(1-\alpha_{n}\right)\left\|T_{r_{n}}\left(x_{n}\right)-p\right\|+\alpha_{n}\|u-p\| \\
& \leq\left(1-\alpha_{n}\right)\left\|x_{n}-p\right\|+\alpha_{n}\|u-p\| \\
& \leq \max \left\{\left\|x_{n}-p\right\|,\|u-p\|\right\} \\
& \vdots \\
& \leq \max \left\{\left\|x_{0}-p\right\|,\|u-p\|\right\} .
\end{aligned}
$$

Thus, $\left\{x_{n}\right\}$ is bounded, and hence so is $\left\{u_{n}\right\}$. 
With the help of the geometric properties of a Hilbert space, from the closed convexity of $\operatorname{MEP}(F, \varphi)$, for $u \in K$, there exists a unique nearest point $x^{*} \in \operatorname{MEP}(F, \varphi)$, that is, $x^{*}=$ $P_{\mathrm{MEP}(F, \varphi)} u$. By equation (2.1) and Lemma 2.2(2), (3), for each fixed $n$, we also have

$$
\begin{aligned}
\left\|x_{n+1}-x^{*}\right\|^{2} & =\left\|\alpha_{n}\left(u-x^{*}\right)+\left(1-\alpha_{n}\right)\left(u_{n}-x^{*}\right)\right\|^{2} \\
& \leq \alpha_{n}\left\|u-x^{*}\right\|^{2}+\left(1-\alpha_{n}\right)\left\|T_{r_{n}}\left(x_{n}\right)-x^{*}\right\|^{2} \\
& \leq\left\|T_{r_{n}}\left(x_{n}\right)-x^{*}\right\|^{2}+\alpha_{n}\left\|u-x^{*}\right\|^{2} \\
& \leq\left\|x_{n}-x^{*}\right\|^{2}-\left\|x_{n}-T_{r_{n}}\left(x_{n}\right)\right\|^{2}+\alpha_{n}\left\|u-x^{*}\right\|^{2},
\end{aligned}
$$

which can be rewritten as

$$
\left\|x_{n}-u_{n}\right\|^{2} \leq \alpha_{n} M+\left\|x_{n}-x^{*}\right\|^{2}-\left\|x_{n+1}-x^{*}\right\|^{2},
$$

where $M=\left\|u-x^{*}\right\|^{2}$. Following the proof technique in Mainge [29, Lemma 3.2, Theorem 3.1], the proof may be divided into two cases.

Case 1. If there exists $N_{0}$ such that the sequence $\left\{\left\|x_{n}-x^{*}\right\|^{2}\right\}$ is nonincreasing for $n \geq N_{0}$,

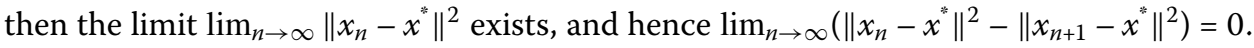
So, by the condition (C1) and inequality (3.2), we have

$$
\lim _{n \rightarrow \infty}\left\|x_{n}-u_{n}\right\|=0
$$

Next, we show

$$
\limsup _{n \rightarrow \infty}\left\langle u-x^{*}, u_{n}-x^{*}\right\rangle \leq 0 \text {. }
$$

Indeed, we can take a subsequence $\left\{u_{n_{k}}\right\}$ of $\left\{u_{n}\right\}$ such that

$$
\limsup _{n \rightarrow \infty}\left\langle u-x^{*}, u_{n}-x^{*}\right\rangle=\lim _{k \rightarrow \infty}\left\langle u-x^{*}, u_{n_{k}}-x^{*}\right\rangle \text {. }
$$

Without loss of generality, we may assume that $u_{n_{k}} \rightarrow x$ by the boundedness of $\left\{u_{n}\right\}$. Let us show $x \in \operatorname{MEP}(F, \varphi)$. In fact, the first inequality of (3.1) yields

$$
F\left(u_{n}, y\right)+\varphi(y)-\varphi\left(u_{n}\right)+\frac{1}{r_{n}}\left\langle y-u_{n}, u_{n}-x_{n}\right\rangle \geq 0, \quad \forall y \in K, n \geq 0 .
$$

From the property (A2) of Condition 1.1, we also have

$$
\frac{1}{r_{n}}\left\langle y-u_{n}, u_{n}-x_{n}\right\rangle \geq-F\left(u_{n}, y\right)-\varphi(y)+\varphi\left(u_{n}\right) \geq F\left(y, u_{n}\right)+\varphi\left(u_{n}\right)-\varphi(y)
$$

and hence by replacing $n$ by $n_{k}$, we obtain

$$
\left\langle y-u_{n_{k}}, \frac{u_{n_{k}}-x_{n_{k}}}{r_{n_{k}}}\right\rangle \geq F\left(y, u_{n_{k}}\right)+\varphi\left(u_{n_{k}}\right)-\varphi(y), \quad \forall y \in K .
$$

By passing to the limit in this inequality and by taking into account the condition (C3) and the fact that $\lim _{k \rightarrow \infty} \frac{u_{n_{k}}-x_{n_{k}}}{r_{n_{k}}}=0, u_{n_{k}} \rightarrow x$ and that the bifunction $F(y, \cdot)$ and the function 
$\varphi(\cdot)$ are weak lower-semicontinuous, we deduce that

$$
0 \geq F(y, x)+\varphi(x)-\varphi(y), \quad \forall y \in K .
$$

Now, for $t$ with $0<t \leq 1$ and $y \in K$, let $y_{t}=t y+(1-t) x$. Since $y \in K$ and $x \in K$, we have $y_{t} \in K$, and hence $0 \geq F\left(y_{t}, x\right)+\varphi(x)-\varphi\left(y_{t}\right)$. So, by virtue of (A1), (A4) of the bifunction $F$ and convexity of the function $\varphi$, we get

$$
\begin{aligned}
0 & =F\left(y_{t}, y_{t}\right)+\varphi\left(y_{t}\right)-\varphi\left(y_{t}\right) \\
& \leq t F\left(y_{t}, y\right)+(1-t) F\left(y_{t}, x\right)+t \varphi(y)+(1-t) \varphi(x)-\varphi\left(y_{t}\right) \\
& =t F\left(y_{t}, y\right)+t\left(\varphi(y)-\varphi\left(y_{t}\right)\right)+(1-t)\left(F\left(y_{t}, x\right)+\varphi(x)-\varphi\left(y_{t}\right)\right) \\
& \leq t\left(F\left(y_{t}, y\right)+\varphi(y)-\varphi\left(y_{t}\right)\right) .
\end{aligned}
$$

Consequently, we deduce

$$
F\left(y_{t}, y\right)+\varphi(y)-\varphi\left(y_{t}\right) \geq 0, \quad \forall y \in K .
$$

In the light of (A3) of the bifunction $F$ and lower-semicontinuity of the function $\varphi$, we have

$$
F(x, y)+\varphi(y)-\varphi(x) \geq 0, \quad \forall y \in K
$$

thus $x \in \operatorname{MEP}(F, \varphi)$. Since $x^{*}=P_{\operatorname{MEP}(F, \varphi)} u$, then by (2.2), we have

$$
\limsup _{n \rightarrow \infty}\left\langle u-x^{*}, u_{n}-x^{*}\right\rangle=\lim _{k \rightarrow \infty}\left\langle u-x^{*}, u_{n_{k}}-x^{*}\right\rangle=\left\langle u-x^{*}, x-x^{*}\right\rangle \leq 0 .
$$

Now, we show that $x_{n} \rightarrow x^{*}(n \rightarrow \infty)$. In fact, from the second equality of (3.1) and $x^{*} \in F\left(T_{r}\right)=\operatorname{MEP}(F, \varphi)$ for each $r>0$ together with Lemma 2.2(2), it follows

$$
\begin{aligned}
\left\|x_{n+1}-x^{*}\right\|^{2}= & \left\|\alpha_{n}\left(u-x^{*}\right)+\left(1-\alpha_{n}\right)\left(u_{n}-x^{*}\right)\right\|^{2} \\
= & \alpha_{n}^{2}\left\|u-x^{*}\right\|^{2}+\left(1-\alpha_{n}\right)^{2}\left\|u_{n}-x^{*}\right\|^{2} \\
& +2 \alpha_{n}\left(1-\alpha_{n}\right)\left(u-x^{*}, u_{n}-x^{*}\right\rangle \\
\leq & \left(1-\alpha_{n}\right)\left\|T_{r_{n}}\left(x_{n}\right)-T_{r_{n}}\left(x^{*}\right)\right\|^{2}+\alpha_{n} \beta_{n} \\
\leq & \left(1-\alpha_{n}\right)\left\|x_{n}-x^{*}\right\|^{2}+\alpha_{n} \beta_{n},
\end{aligned}
$$

which can be rewritten as

$$
\left\|x_{n+1}-x^{*}\right\|^{2} \leq\left(1-\alpha_{n}\right)\left\|x_{n}-x^{*}\right\|^{2}+\alpha_{n} \beta_{n},
$$

where $\beta_{n}=\alpha_{n}\left\|u-x^{*}\right\|^{2}+2\left(1-\alpha_{n}\right)\left\langle u-x^{*}, u_{n}-x^{*}\right\rangle$. From the condition (C1) and (3.4), we obtain

$$
\limsup _{n \rightarrow \infty} \beta_{n}=\limsup _{n \rightarrow \infty}\left(\alpha_{n}\left\|u-x^{*}\right\|^{2}+2\left(1-\alpha_{n}\right)\left\langle u-x^{*}, u_{n}-x^{*}\right\rangle\right) \leq 0 .
$$


So, an application of Lemma 2.3 onto (3.5) yields $x_{n} \rightarrow x^{*}$.

Case 2. Assume that there exists a subsequence $\left\{\left\|x_{n_{k}}-x^{*}\right\|^{2}\right\}$ of $\left\{\left\|x_{n}-x^{*}\right\|^{2}\right\}$ such that $\left\|x_{n_{k}}-x^{*}\right\|^{2}<\left\|x_{n_{k}+1}-x^{*}\right\|^{2}$ for all $k \geq 0$. Let

$$
\Gamma_{n}=\left\|x_{n}-x^{*}\right\|^{2} \text { and } \tau(n)=\max \left\{k \leq n ; \Gamma_{k}<\Gamma_{k+1}\right\} .
$$

It follows from Mainge [29, Lemma 3.1] that $\tau(n)$ is a nondecreasing sequence verifying $\lim _{n \rightarrow \infty} \tau(n)=+\infty$, and for $n$ large enough,

$$
\Gamma_{\tau(n)} \leq \Gamma_{\tau(n)+1}, \quad \Gamma_{n}=\left\|x_{n}-x^{*}\right\|^{2} \leq \Gamma_{\tau(n)+1} .
$$

In light of equation (3.2), we have $\left\|x_{\tau(n)}-u_{\tau(n)}\right\|^{2} \leq \alpha_{\tau(n)} M$, and so by the condition (C1), we have

$$
\lim _{n \rightarrow \infty}\left\|x_{\tau(n)}-u_{\tau(n)}\right\|=0
$$

Using the similar proof techniques as in Case 1 , the only modification being that $n\left(n_{k}\right)$ is replaced by $\tau(n)\left(\tau\left(n_{k}\right)\right.$, respectively), we have

$$
\limsup _{n \rightarrow \infty}\left\langle u-x^{*}, u_{\tau(n)}-x^{*}\right\rangle \leq 0
$$

and

$$
\left\|x_{\tau(n)+1}-x^{*}\right\|^{2} \leq\left(1-\alpha_{\tau(n)}\right)\left\|x_{\tau(n)}-x^{*}\right\|^{2}+\alpha_{\tau(n)} \beta_{\tau(n)},
$$

where $\beta_{\tau(n)}=\alpha_{\tau(n)}\left\|u-x^{*}\right\|^{2}+2\left(1-\alpha_{\tau(n)}\right)\left\langle u-x^{*}, u_{\tau(n)}-x^{*}\right\rangle$, and so

$$
\limsup _{n \rightarrow \infty} \beta_{\tau(n)} \leq 0
$$

By (3.6), we have

$$
\Gamma_{\tau(n)} \leq \Gamma_{\tau(n)+1} \leq\left(1-\alpha_{\tau(n)}\right) \Gamma_{\tau(n)}+\alpha_{\tau(n)} \beta_{\tau(n)},
$$

and hence

$$
\Gamma_{\tau(n)} \leq \beta_{\tau(n)} .
$$

So, we obtain

$$
\lim _{n \rightarrow \infty} \Gamma_{\tau(n)}=\lim _{n \rightarrow \infty}\left\|x_{\tau(n)}-x^{*}\right\|=0 .
$$

Together with (3.9), we have

$$
\lim _{n \rightarrow \infty}\left\|x_{\tau(n)+1}-x^{*}\right\|=\lim _{n \rightarrow \infty}\left\|x_{\tau(n)}-x^{*}\right\|=0 .
$$

Now, it follows from (3.6) that $\Gamma_{n}=\left\|x_{n}-x^{*}\right\| \rightarrow 0$. The proof is completed. 


\section{Weak convergence of Algorithm 2}

In this section, we show a weak convergence theorem which solves the MEP (1.1) in a Hilbert space.

Theorem 4.1 Let $K$ be a nonempty closed convex subset of a real Hilbert space H. Assume that $a$ bifunction $F$ and a function $\varphi$ satisfy Condition 1.1 and $\operatorname{MEP}(F, \varphi) \neq \emptyset$. For any initialization $x_{0} \in K$, if $x_{n}(n \geq 0)$ is the current iterate and positive real numbers $\alpha_{n}, r_{n}$ are the current parameters, then $x_{n+1} \in K$ is given iteratively by

$$
\left\{\begin{array}{l}
F\left(u_{n}, y\right)+\varphi(y)-\varphi\left(u_{n}\right)+\frac{1}{r_{n}}\left\langle y-u_{n}, u_{n}-x_{n}\right\rangle \geq 0 \\
x_{n+1}=\alpha_{n} x_{n}+\left(1-\alpha_{n}\right) u_{n}, \quad \forall y \in K, n \geq 0
\end{array}\right.
$$

Assume that $\left\{\alpha_{n}\right\} \subset(0,1)$ satisfies (C4) $\limsup _{n \rightarrow \infty} \alpha_{n}<1$. Then

$$
\sum_{n=0}^{+\infty}\left\|u_{n}-x_{n}\right\|^{2}<+\infty
$$

If, in addition, $\left\{r_{n}\right\} \subset(0,+\infty)$ satisfies (C3) $\liminf _{n \rightarrow \infty} r_{n}>0$, then $\left\{x_{n}\right\}$ and $\left\{u_{n}\right\}$ converge weakly to some element $x$ of $\operatorname{MEP}(F, \varphi)$.

Proof Take $p \in \operatorname{MEP}(F, \varphi)$. It follows from Lemma 2.2 that $u_{n}=T_{r_{n}}\left(x_{n}\right)$ and

$$
\begin{aligned}
\left\|x_{n+1}-p\right\| & \leq\left(1-\alpha_{n}\right)\left\|T_{r_{n}}\left(x_{n}\right)-p\right\|+\alpha_{n}\left\|x_{n}-p\right\| \\
& \leq\left(1-\alpha_{n}\right)\left\|x_{n}-p\right\|+\alpha_{n}\left\|x_{n}-p\right\| \\
& \leq\left\|x_{n}-p\right\| \\
& \vdots \\
& \leq\left\|x_{0}-p\right\| .
\end{aligned}
$$

So, $\left\{x_{n}\right\}$ and $\left\{u_{n}\right\}$ are bounded. Moreover, the limit $\lim _{n \rightarrow \infty}\left\|x_{n}-p\right\|$ exists for each $p \in$ $\operatorname{MEP}(F, \varphi)$.

It follows from equation (2.1) and Lemma 2.2(2), (3) that for each fixed $n$,

$$
\begin{aligned}
\left\|x_{n+1}-p\right\|^{2} & =\left\|\alpha_{n}\left(x_{n}-p\right)+\left(1-\alpha_{n}\right)\left(u_{n}-p\right)\right\|^{2} \\
& \leq \alpha_{n}\left\|x_{n}-p\right\|^{2}+\left(1-\alpha_{n}\right)\left\|T_{r_{n}}\left(x_{n}\right)-p\right\|^{2} \\
& \leq \alpha_{n}\left\|x_{n}-p\right\|^{2}+\left(1-\alpha_{n}\right)\left(\left\|x_{n}-p\right\|^{2}-\left\|x_{n}-T_{r_{n}}\left(x_{n}\right)\right\|^{2}\right) \\
& \leq\left\|x_{n}-p\right\|^{2}-\left(1-\alpha_{n}\right)\left\|x_{n}-T_{r_{n}}\left(x_{n}\right)\right\|^{2},
\end{aligned}
$$

which can be rewritten as

$$
\left(1-\alpha_{n}\right)\left\|x_{n}-u_{n}\right\|^{2} \leq\left\|x_{n}-p\right\|^{2}-\left\|x_{n+1}-p\right\|^{2} .
$$

Therefore, we obtain

$$
\sum_{n=0}^{m}\left(1-\alpha_{n}\right)\left\|x_{n}-u_{n}\right\|^{2} \leq\left\|x_{0}-p\right\|^{2}-\left\|x_{m}-p\right\|^{2} \leq\left\|x_{0}-p\right\|^{2},
$$


and hence

$$
\sum_{n=0}^{+\infty}\left(1-\alpha_{n}\right)\left\|x_{n}-u_{n}\right\|^{2}<+\infty
$$

Since $\left\{\alpha_{n}\right\} \subset(0,1)$ satisfies (C4) lim $\sup _{n \rightarrow \infty} \alpha_{n}<1$, then there exists $a \in(0,1)$ and $N$ sufficiently large such that $0<\alpha_{n} \leq a<1$ for all $n>N$, which implies $(1-a)\left\|x_{n}-u_{n}\right\|^{2} \leq$ $\left(1-\alpha_{n}\right)\left\|x_{n}-u_{n}\right\|^{2}$. Consequently,

$$
\sum_{n=0}^{+\infty}\left\|x_{n}-u_{n}\right\|^{2}<+\infty
$$

and so

$$
\lim _{n \rightarrow \infty}\left\|x_{n}-u_{n}\right\|=0
$$

Therefore, the limit $\lim _{n \rightarrow \infty}\left\|u_{n}-p\right\|$ exists for each $p \in \operatorname{MEP}(F, \varphi)$ since $\left\|x_{n}-p\right\|-\| x_{n}-$ $u_{n}\|\leq\| u_{n}-p\|\leq\| x_{n}-p \|$.

By properties of Hilbert spaces, the boundedness of $\left\{u_{n}\right\}$ means that the sequence $\left\{u_{n}\right\}$ is weak compact in $H$, and hence there exists a subsequence $\left\{u_{n_{k}}\right\}$ of $\left\{u_{n}\right\}$ such that $u_{n_{k}} \rightarrow x$. Then using the same argument as in the proof of Theorem 3.1 by means of (4.3) and the condition (C3) together with the properties of the bifunction $F$ and the function $\varphi$, we must have $x \in \operatorname{MEP}(F, \varphi)$.

Next, we show that there is a unique weak cluster point $x$ of the sequence $\left\{u_{n}\right\}$, that is, $u_{n} \rightarrow x$. This fact can be reached from the Opial property of $H$ and the existence of $\lim _{n \rightarrow \infty}\left\|u_{n}-p\right\|$ for each $p \in \operatorname{MEP}(F, \varphi)$. The proof is presented here for completeness. Indeed, let $z$ be another weak cluster point of $\left\{u_{n}\right\}$, write as $u_{n_{i}} \rightarrow z$. Then we also have $z \in \operatorname{MEP}(F, \varphi)$. Let us show that $x=z$. For $x, z$, we have

$$
\left\|u_{n_{i}}-x\right\|^{2}=\left\|u_{n_{i}}-z\right\|^{2}+\|z-x\|^{2}+2\left\langle u_{n_{i}}-z, z-x\right\rangle
$$

and

$$
\left\|u_{n_{k}}-z\right\|^{2}=\left\|u_{n_{k}}-x\right\|^{2}+\|x-z\|^{2}+2\left\langle u_{n_{k}}-x, x-z\right\rangle .
$$

Since both $\lim _{n \rightarrow \infty}\left\|u_{n}-x\right\|$ and $\lim _{n \rightarrow \infty}\left\|u_{n}-z\right\|$ exist, $\lim _{i \rightarrow \infty}\left\langle u_{n_{i}}-z, z-x\right\rangle=0$ and $\lim _{k \rightarrow \infty}\left\langle u_{n_{k}}-x, x-z\right\rangle=0$, then

$$
\lim _{n \rightarrow \infty}\left\|u_{n}-x\right\|^{2}=\lim _{n \rightarrow \infty}\left\|u_{n}-z\right\|^{2}+\|z-x\|^{2}
$$

and

$$
\lim _{n \rightarrow \infty}\left\|u_{n}-z\right\|^{2}=\lim _{n \rightarrow \infty}\left\|u_{n}-x\right\|^{2}+\|x-z\|^{2}
$$

Adding the above equations, we must have $2\|x-z\|^{2}=0$, and so $x=z$. This implies $u_{n} \rightarrow$ $x \in \operatorname{MEP}(F, \varphi)$. By (4.3), it is obvious that $\left\{x_{n}\right\}$ also converges weakly to $x$. The desired results are reached. 


\section{Deduced results and some remarks}

Let $K$ be a nonempty closed convex subset of a real Hilbert space $H$. We recall that a mapping $T: K \rightarrow H$ is said to be monotone if

$$
\langle T x-T y, x-y\rangle \geq 0 \quad \text { for all } x, y \in K .
$$

A continuous monotone mapping has the following properties which were given in Nilsrakoo and Saejung [23] and Combettes and Hirstoaga [3] independently.

Lemma 5.1 (Combettes and Hirstoaga [3, Lemma 2.15], Nilsrakoo and Saejung [23, Lemmas 19, 20]) Let $K$ be a nonempty closed convex subset of a real Hilbert space H. Let $T$ be a continuous monotone mapping of $K$ into $H$. Define a bifunction $F: K \times K \rightarrow \mathbb{R}$ as follows:

$$
F(x, y):=\langle T x, y-x\rangle \text { for all } x, y \in K \text {. }
$$

Then the following hold:

(i) F satisfies (A1)-(A4) in Condition 1.1 and $\operatorname{VIP}(K, T)=\mathrm{EP}(F)$;

(ii) for $x \in H, z \in K$ and $r>0$,

$$
F(z, y)+\frac{1}{r}\langle y-z, z-x\rangle \geq 0, \quad \forall y \in K \quad \Leftrightarrow \quad z=P_{K}(x-r T z) .
$$

Using Theorems 3.1 and 4.1 along with Lemma 5.1, we have the following theorems which solve GVIP (1.5) and VIP (1.4) under the simpler framework.

Theorem 5.2 Let $K$ be a nonempty closed convex subset of $H$ and $T$ be a continuous monotone mapping of $K$ such that $\operatorname{VIP}(K, T) \neq \emptyset$. For any anchor $u \in K$ and initialization $x_{0} \in K$,

(1) let $\left\{x_{n}\right\}$ and $\left\{u_{n}\right\}$ be sequences generated iteratively by

$$
\left\{\begin{array}{l}
u_{n}=P_{K}\left(x_{n}-r_{n} T u_{n}\right), \\
x_{n+1}=\alpha_{n} u+\left(1-\alpha_{n}\right) u_{n} .
\end{array}\right.
$$

Assume that $\alpha_{n} \in(0,1)$ and $r_{n} \in(0,+\infty)$ satisfy

$$
\text { (C1) } \lim _{n \rightarrow \infty} \alpha_{n}=0, \quad(\mathrm{C} 2) \sum_{n=1}^{+\infty} \alpha_{n}=+\infty \quad \text { and } \quad \text { (C3) } \liminf _{n \rightarrow \infty} r_{n}>0
$$

Then $\left\{x_{n}\right\}$ converges strongly to $x^{*} \in \operatorname{VIP}(K, T)$, which is the nearest point from $K$ to $\operatorname{VIP}(K, T)$;

(2) let $\left\{x_{n}\right\}$ and $\left\{u_{n}\right\}$ be sequences generated iteratively by

$$
\left\{\begin{array}{l}
u_{n}=P_{K}\left(x_{n}-r_{n} T u_{n}\right), \\
x_{n+1}=\alpha_{n} x_{n}+\left(1-\alpha_{n}\right) u_{n},
\end{array}\right.
$$

where $r_{n} \in(0,+\infty)$ and $\alpha_{n} \in(0,1)$ satisfy $(\mathrm{C} 3)$ and $(\mathrm{C} 4) \lim _{\sup } \operatorname{su}_{n \rightarrow \infty} \alpha_{n}<1$. Then $\left\{x_{n}\right\}$ converges weakly to some $x^{*} \in \operatorname{VIP}(K, T)$. 
Proof Let $F(x, y)=\langle T x, y-x\rangle$ for all $x, y \in K$. It follows from Lemma 5.1 that two iteration schemes (5.1) and (5.2) respectively turn into

$$
\left\{\begin{array}{l}
F\left(u_{n}, y\right)+\frac{1}{r_{n}}\left\langle y-u_{n}, u_{n}-x_{n}\right\rangle \geq 0 \\
x_{n+1}=\alpha_{n} u+\left(1-\alpha_{n}\right) u_{n}, \quad \forall y \in K, n \geq 0
\end{array}\right.
$$

and

$$
\left\{\begin{array}{l}
F\left(u_{n}, y\right)+\frac{1}{r_{n}}\left\langle y-u_{n}, u_{n}-x_{n}\right\rangle \geq 0 \\
x_{n+1}=\alpha_{n} x_{n}+\left(1-\alpha_{n}\right) u_{n}, \quad \forall y \in K, n \geq 0
\end{array}\right.
$$

Following Theorems 3.1 and $4.1(\varphi \equiv 0)$, the desired results are proved.

Theorem 5.3 Let $K$ be a nonempty closed convex subset of $H, \varphi$ be a convex and lower semicontinuous function from $K$ to $\mathbb{R}$, and $T$ be a continuous monotone mapping of $K$ such that $\operatorname{GVIP}(K, \varphi, T) \neq \emptyset$. For any anchor $u \in K$ and initialization $x_{0} \in K$,

(1) let $\left\{x_{n}\right\}$ and $\left\{u_{n}\right\}$ be sequences generated iteratively by

$$
\left\{\begin{array}{l}
\left\langle T u_{n}, y-u_{n}\right\rangle+\varphi(y)-\varphi\left(u_{n}\right)+\frac{1}{r_{n}}\left\langle y-u_{n}, u_{n}-x_{n}\right\rangle \geq 0 \\
x_{n+1}=\alpha_{n} u+\left(1-\alpha_{n}\right) u_{n}, \quad \forall y \in K, n \geq 0
\end{array}\right.
$$

where $\alpha_{n} \in(0,1)$ and $r_{n} \in(0,+\infty)$ satisfy $(\mathrm{C} 1),(\mathrm{C} 2)$ and $(\mathrm{C} 3)$. Then $\left\{x_{n}\right\}$ converges strongly to $x^{*} \in \operatorname{GVIP}(K, \varphi, T)$, which is the nearest point from $K$ to $\operatorname{GVIP}(K, \varphi, T)$;

(2) let $\left\{x_{n}\right\}$ and $\left\{u_{n}\right\}$ be sequences generated iteratively by

$$
\left\{\begin{array}{l}
\left\langle T u_{n}, y-u_{n}\right\rangle+\varphi(y)-\varphi\left(u_{n}\right)+\frac{1}{r_{n}}\left\langle y-u_{n}, u_{n}-x_{n}\right\rangle \geq 0 \\
x_{n+1}=\alpha_{n} x_{n}+\left(1-\alpha_{n}\right) u_{n}, \quad \forall y \in K, n \geq 0
\end{array}\right.
$$

where $r_{n} \in(0,+\infty)$ and $\alpha_{n} \in(0,1)$ satisfy $(\mathrm{C} 3)$ and $(\mathrm{C} 4)$. Then $\left\{x_{n}\right\}$ converges weakly to some $x^{*} \in \operatorname{GVIP}(K, \varphi, T)$.

Proof Let $F(x, y)=\langle T x, y-x\rangle$ for all $x, y \in K$. It follows from Lemma 5.1, Theorems 3.1 and 4.1, the desired results are obtained.

For the classical equilibrium problem (1.2), the following is obvious $(\varphi \equiv 0$ in Theorems 3.1 and 4.1).

Theorem 5.4 Let $K$ be a nonempty closed convex subset of $H$ and $F$ be a bifunction from $K \times K$ to $\mathbb{R}$ such that (A1)-(A4) of Condition 1.1 and $\operatorname{EP}(F) \neq \emptyset$. For any anchor $u \in K$ and initialization $x_{0} \in K$,

(1) let $\left\{x_{n}\right\}$ and $\left\{u_{n}\right\}$ be sequences generated iteratively by

$$
\left\{\begin{array}{l}
F\left(u_{n}, y\right)+\frac{1}{r_{n}}\left\langle y-u_{n}, u_{n}-x_{n}\right\rangle \geq 0, \quad \forall y \in K \\
x_{n+1}=\alpha_{n} u+\left(1-\alpha_{n}\right) u_{n}, \quad n \geq 0
\end{array}\right.
$$


where $\alpha_{n} \in(0,1)$ and $r_{n} \in(0,+\infty)$ satisfy $(\mathrm{C} 1),(\mathrm{C} 2)$ and $(\mathrm{C} 3)$. Then $\left\{x_{n}\right\}$ converges strongly to $x^{*} \in \mathrm{EP}(F)$, which is the nearest point from $K$ to $\mathrm{EP}(F)$;

(2) let $\left\{x_{n}\right\}$ and $\left\{u_{n}\right\}$ be sequences generated iteratively by

$$
\left\{\begin{array}{l}
F\left(u_{n}, y\right)+\frac{1}{r_{n}}\left\langle y-u_{n}, u_{n}-x_{n}\right\rangle \geq 0, \quad \forall y \in K, \\
x_{n+1}=\alpha_{n} x_{n}+\left(1-\alpha_{n}\right) u_{n}, \quad n \geq 0,
\end{array}\right.
$$

where $r_{n} \in(0,+\infty)$ and $\alpha_{n} \in(0,1)$ satisfy $(\mathrm{C} 3)$ and $(\mathrm{C} 4)$. Then $\left\{x_{n}\right\}$ converges weakly to some $x^{*} \in \mathrm{EP}(F)$.

When $F \equiv 0$ in Theorems 3.1 and 4.1, we also have better approximated algorithm about solving the minimization problem (1.3) of a function $\varphi$.

Theorem 5.5 Let $K$ be a nonempty closed convex subset of $H$ and $\varphi$ be a convex and lowercontinuous function from $K$ to $\mathbb{R}$ such that $\operatorname{Argmin}(\varphi) \neq \emptyset$. For any anchor $u \in K$ and initialization $x_{0} \in K$,

(1) let $\left\{x_{n}\right\}$ and $\left\{u_{n}\right\}$ be sequences generated iteratively by

$$
\left\{\begin{array}{l}
\varphi(y)-\varphi\left(u_{n}\right)+\frac{1}{r_{n}}\left\langle y-u_{n}, u_{n}-x_{n}\right\rangle \geq 0, \quad \forall y \in K, \\
x_{n+1}=\alpha_{n} u+\left(1-\alpha_{n}\right) u_{n}, \quad n \geq 0,
\end{array}\right.
$$

where $\alpha_{n} \in(0,1)$ and $r_{n} \in(0,+\infty)$ satisfy $(\mathrm{C} 1),(\mathrm{C} 2)$ and $(\mathrm{C} 3)$. Then $\left\{x_{n}\right\}$ converges strongly to $x^{\prime \prime} \in \operatorname{Argmin}(\varphi)$, which is the nearest point from $K$ to $\operatorname{Argmin}(\varphi)$;

(2) let $\left\{x_{n}\right\}$ and $\left\{u_{n}\right\}$ be sequences generated iteratively by

$$
\left\{\begin{array}{l}
\varphi(y)-\varphi\left(u_{n}\right)+\frac{1}{r_{n}}\left\langle y-u_{n}, u_{n}-x_{n}\right\rangle \geq 0, \quad \forall y \in K, \\
x_{n+1}=\alpha_{n} x_{n}+\left(1-\alpha_{n}\right) u_{n}, \quad n \geq 0,
\end{array}\right.
$$

where $r_{n} \in(0,+\infty)$ and $\alpha_{n} \in(0,1)$ satisfy $(\mathrm{C} 3)$ and $(\mathrm{C} 4)$. Then $\left\{x_{n}\right\}$ converges weakly to some $x^{\prime \prime} \in \operatorname{Argmin}(\varphi)$.

We also observe the condition (C4) that $\lim _{\sup _{n \rightarrow \infty}} \alpha_{n}<1$ includes the case that $\alpha_{n}=0$ as a special case. Therefore, our iteration scheme contains several proximal point algorithms that compute the solution $x_{n+1} \in K$ of some regularized problem.

Theorem 5.6 Let $K$ be a nonempty closed convex subset of a real Hilbert space H. Assume that a bifunction $F$ and a function $\varphi$ satisfy Condition 1.1 and $\operatorname{MEP}(F, \varphi) \neq \emptyset$. Let $T$ be a continuous monotone mapping of $K$ such that $\operatorname{GVIP}(K, \varphi, T) \neq \emptyset$. For any initialization $x_{0} \in K$, if $x_{n}(n \geq 0)$ is the current iterate and a positive real number $r_{n}$ is the current parameter, then $x_{n+1}$ is defined by computing the solution of the regularized problem

$$
F\left(x_{n+1}, y\right)+\varphi(y)-\varphi\left(x_{n+1}\right)+\frac{1}{r_{n}}\left\langle y-x_{n+1}, x_{n+1}-x_{n}\right\rangle \geq 0, \quad \forall y \in K
$$

or

$$
\left\langle T x_{n+1}, y-x_{n+1}\right\rangle+\varphi(y)-\varphi\left(x_{n+1}\right)+\frac{1}{r_{n}}\left\langle y-x_{n+1}, x_{n+1}-x_{n}\right\rangle \geq 0, \quad \forall y \in K .
$$


Then

$$
\sum_{n=0}^{+\infty}\left\|x_{n+1}-x_{n}\right\|^{2}<+\infty
$$

If, in addition, $\left\{r_{n}\right\} \subset(0,+\infty)$ satisfies (C3) $\liminf _{n \rightarrow \infty} r_{n}>0$, then

(i) $\left\{x_{n}\right\}$, given by (5.9) converge weakly to some element $x$ of $\operatorname{MEP}(F, \varphi)$;

(ii) $\left\{x_{n}\right\}$, given by (5.10) converge weakly to some element $x$ of $\operatorname{GVIP}(K, \varphi, T)$.

Proof It follows from Lemma 2.2 or Lemma 5.1 together with (5.9) or (5.10) that $x_{n+1}=$ $T_{r_{n}}\left(x_{n}\right)$. Then by Theorem 4.1, the desired results are obtained.

Remark 5.7 (1) By particularizing the bifunction $F$, the function $\varphi$ and the parameters $\alpha_{n}, r_{n}$, some other methods and related results can be derived from our main theorems. For example, taking $\varphi \equiv 0$ in (5.9) and $\lim _{n \rightarrow \infty} r_{n}=+\infty$ in (5.5), we obtain several main results in Combettes and Hirstoaga [3], and in the case where (C3), $\sum_{n=0}^{+\infty}\left\|r_{n}-r_{n+1}\right\|<+\infty$ and $\sum_{n=0}^{+\infty} \alpha_{n}\left(1-\alpha_{n}\right)=+\infty$ in (5.6), we have the main result in Nilsrakoo and Saejung [23], and when taking $\alpha_{n} \in[a, b] \subset(0,1)$ in (5.6), a result is proved by Tada and Takahashi [21], and if $\alpha_{n} \equiv 0$ in (5.2), then we obtain Algorithm 2 and Theorem 5 in Solodov and Svaiter $[24]$; also see $[4,5,8,20]$ and others for varying versions.

(2) All strong convergence theorems of this paper remain true if one replaces the anchor point $u$ by a contraction $f$ (that is, so-called viscosity approximation methods with a contraction $f$ ) since Song [30] has showed their equivalency. So our main results could recover or develop some viscosity approximation results such as ones in references $[8,10,11,13]$ as well as others not referenced here.

(3) The framework of holding our conclusions is more general and our results treat several iterative schemes and corresponding results in a united way. Consequently, our main results could be considered as recovering, developing and improving some known related convergence results in this field.

\footnotetext{
Competing interests

The authors declare that they have no competing interests
}

\section{Authors' contributions}

The work presented here was carried out in collaboration between all authors. All authors contributed equally and significantly to writing this manuscript. All authors have contributed to, seen and approved the final manuscript.

\section{Author details}

${ }^{1}$ College of Mathematics and Information Science, Henan Normal University, Xinxiang, Henan 453007, P.R. China. ${ }^{2}$ Department of Applied Mathematics, The Hong Kong Polytechnic University, Hung Hom, Kowloon, Hong Kong, P.R. China. ${ }^{3}$ College of Mathematics and Information Science, North China University of Water Resources and Electric Power, Zhengzhou, 450011, P.R. China.

\section{Acknowledgements}

The authors would like to thank the editor and the anonymous referee for useful comments and valuable suggestions on the language and structure of our manuscript. This work is supported by the National Natural Science Foundation of P.R. China (11071279, 11171094, 11271112).

Received: 21 February 2012 Accepted: 17 September 2012 Published: 2 October 2012

\section{References}

1. Moudafi, A: Proximal point algorithm extended for equilibrium problems. J. Nat. Geom. 15, 91-100 (1999)

2. Konnov, IV: Application of the proximal point method to nonmonotone equilibrium problems. J. Optim. Theory Appl. 119, 317-333 (2003) 
3. Combettes, PL, Hirstoaga, SA: Equilibrium programming in Hilbert spaces. J. Nonlinear Convex Anal. 6, 117-136 (2005)

4. Song, Y, Zheng, Y: Strong convergence of iteration algorithms for a countable family of nonexpansive mappings. Nonlinear Anal. 71(7-8), 3072-3082 (2009)

5. Song, Y, Kang, Jl, Cho, YJ: On iterations methods for zeros of accretive operators in Banach spaces. Appl. Math. Comput. 216, 1007-1017 (2010)

6. Tran, DQ, Muu, LD, Nguyen, VH: Extragradient algorithms extended to solving equilibrium problems. Optimization 57(6), 749-776 (2008)

7. Van, NTT, Strodiot, JJ, Nguyen, VH: A bundle method for solving equilibrium problems. Math. Program., Ser. B 116(1-2), 529-552 (2009)

8. Takahashi, S, Takahashi, W: Viscosity approximation methods for equilibrium problems and fixed point problems in Hilbert spaces. J. Math. Anal. Appl. 331(1), 506-515 (2007)

9. Plubtieng, S, Thammathiwat, T: A viscosity approximation method for equilibrium problems, fixed point problems of nonexpansive mappings and a general system of variational inequalities. J. Glob. Optim. 46, 447-464 (2010)

10. Qin, X, Cho, YJ, Kang, SM: Viscosity approximation methods for generalized equilibrium problems and fixed point problems with applications. Nonlinear Anal. 72,99-112 (2010)

11. Qin, X, Cho, YJ, Kang, SM: Convergence theorems of common elements for equilibrium problems and fixed point problems in Banach spaces. J. Comput. Appl. Math. 225, 20-30 (2009)

12. Qin, X, Shang, M, Su, Y: Strong convergence of a general iterative algorithm for equilibrium problems and variational inequality problems. Math. Comput. Model. 48, 1033-1046 (2008)

13. Qin, $X$, Shang, M, Su, Y: A general iterative method for equilibrium problems and fixed point problems in Hilbert spaces. Nonlinear Anal. 69, 3897-3909 (2008)

14. Moudafi, A: Proximal methods for a class of bilevel monotone equilibrium problems. J. Glob. Optim. 47, 287-292 (2010)

15. Ceng, LC, Yao, JC: A hybrid iterative scheme for mixed equilibrium problems and fixed point problems. J. Comput. Appl. Math. 214, 186-201 (2008)

16. Peng, JW, Liou, YC, Yao, JC: An iterative algorithm combining viscosity method with parallel method for a generalized equilibrium problem and strict pseudocontractions. Fixed Point Theory Appl. 2009, Article ID 794178 (2009)

17. Blum, E, Oettli, W: From optimization and variational inequalities to equilibriums problems. Math. Stud. 63, 123-145 (1994)

18. Chadli, O, Chbani, Z, Riahi, H: Equilibrium problems with generalized monotone bifunctions and applications to variational inequalities. J. Optim. Theory Appl. 105(2), 299-323 (2000)

19. Cabot, A: Proximal point algorithm controlled by a slowly vanishing term: applications to hierarchical minimization. SIAM J. Optim. 15(2), 555-572 (2005)

20. Iusem, AN, Sosa, W: Iterative algorithms for equilibrium problems. Optimization 52, 301-316 (2003)

21. Tada, A, Takahashi, W: Weak and strong convergence theorems for a nonexpansive mapping and an equilibrium problem. J. Optim. Theory Appl. 133, 359-370 (2007)

22. Yamada, I, Ogura, N: Hybrid steepest descent method for the variational inequality problem over the fixed point set of certain quasi-nonexpansive mappings. Numer. Funct. Anal. Optim. 25(7-8), 619-655 (2004)

23. Nilsrakoo, W, Saejung, S: Weak and strong convergence theorems for countable Lipschitzian mappings and its applications. Nonlinear Anal. 69, 2695-2708 (2008)

24. Solodov, MV, Svaiter, BF: Error bounds for proximal point subproblems and associated inexact proximal point algorithms. Math. Program., Ser. B 88, 371-389 (2000)

25. Liu, LS: Ishikawa and Mann iteration process with errors for nonlinear strongly accretive mappings in Banach spaces. J. Math. Anal. Appl. 194, 114-125 (1995)

26. Xu, HK: An iterative approach to quadratic optimization. J. Optim. Theory Appl. 116, 659-678 (2003)

27. Xu, HK: Iterative algorithms for nonlinear operators. J. Lond. Math. Soc. 66, 240-256 (2002)

28. Reich, S: Constructive techniques for accretive and monotone operators. In: Applied Nonlinear Analysis, pp. $335-345$. Academic Press, New York (1979)

29. Mainge, P-E: Strong convergence of projected subgradient methods for nonsmooth and nonstrictly convex minimization. Set-Valued Anal. 16, 899-912 (2008)

30. Song, Y: Equivalent theorems of the convergence between proximal-type algorithms. Nonlinear Anal. 71, 293-300 (2009)

doi:10.1186/1687-1812-2012-166

Cite this article as: Song and Zhang: Proximal algorithms for a class of mixed equilibrium problems. Fixed Point Theory and Applications 2012 2012:166. 